Abstracta Iranica Abstracta Iranica

Revue bibliographique pour le domaine irano-aryen

Volume 28 | 2007

Comptes rendus des publications de 2005

\title{
American Troops in Afghanistan: Building a new Nation. NY, Rosen Publishing Group, 2005, 45 p.
}

\section{Anicée Van Engeland}

\section{(2) OpenEdition}

1 Journals

\section{Édition électronique}

URL : http://journals.openedition.org/abstractairanica/20121

DOI : 10.4000/abstractairanica.20121

ISSN : 1961-960X

Éditeur :

CNRS (UMR 7528 Mondes iraniens et indiens), Éditions de l'IFRI

\section{Édition imprimée}

Date de publication : 15 mai 2007

ISSN : 0240-8910

\section{Référence électronique}

Anicée Van Engeland, « American Troops in Afghanistan: Building a new Nation. NY, Rosen Publishing Group, 2005, 45 p. », Abstracta Iranica [En ligne], Volume 28 | 2007, document 479, mis en ligne le 18 septembre 2007, consulté le 25 septembre 2020. URL : http://journals.openedition.org/ abstractairanica/20121; DOI : https://doi.org/10.4000/abstractairanica.20121

Ce document a été généré automatiquement le 25 septembre 2020.

Tous droits réservés 


\title{
American Troops in Afghanistan: Building a new Nation. NY, Rosen Publishing Group, 2005, 45 p.
}

\author{
Anicée Van Engeland
}

Cet ouvrage traite des activités post-guerre en Afghanistan, de la reconstruction à la lutte pour conquérir à la fois les cœurs et les esprits afghans par l'armée américaine. Ces efforts rencontrent des obstacles tels la présence de seigneurs de guerre et de seigneurs de drogue, ainsi que de la persistance des Talibans dans certaines poches géographiques. L'A. fait part d'anecdotes afin d'illustrer les difficultés que l'armée américaine rencontre sur le terrain tels que la lutte contre les réseaux terroristes, l'entraînement des recrues de la nouvelle armée afghane, les interactions culturelles et les développements sociaux dûs à l'aide humanitaire et à la présence étrangère. Cet ouvrage offre une perspective unique sur les événements actuels en Afghanistan et l'impact de la présence des troupes américaines sur le développement d'une nouvelle nation.

INDEX

Thèmes : 13.2. Afghanistan 
AUTEURS

ANICÉE VAN ENGELAND

Paris 